\title{
Exclusion of solar UV radiation increases the yield of curcuminoid in Curcuma longa $\mathrm{L}$.
}

\author{
Maria Izabela Ferreira ${ }^{a}$, Maira Rodrigues Uliana ${ }^{\mathrm{b}}$, Sergio Marques Costa ${ }^{\mathrm{a}}$, \\ Massimiliano Magro ${ }^{c}$, Fabio Vianello ${ }^{c}$, Lin Chau Ming ${ }^{\mathrm{d}}$, Giuseppina Pace Pereira Lima ${ }^{\mathrm{a}, *}$ \\ a Department of Chemistry and Biochemistry, Institute of Biosciences, São Paulo State University, CP 510, 18.618-970 Botucatu, São Paulo, Brazil \\ b Universidade do Oeste Paulista, Campus II, Bairro do Limoeiro, 19067-175 Presidente Prudente, São Paulo, Brazil \\ ${ }^{\mathrm{c}}$ Department of Comparative Biomedicine and Food Science, Viale dell'Università, 16, 35020 Legnaro, Padova, Italy \\ d Department of Horticulture, School of Agronomy, São Paulo State University, CP 510, 18.618-970 Botucatu, São Paulo, Brazil
}

\section{A R T I C L E I N F O}

\section{Article history:}

Received 13 January 2016

Received in revised form 23 April 2016

Accepted 5 May 2016

Available online 20 May 2016

\section{Keywords:}

Turmeric

Photosynthesis

Biomass

Polyamine

POD

PAL

\begin{abstract}
A B S T R A C T
In this study, we grew Curcuma longa in field conditions under a range of shade levels and the exclusion of solar UV wavelengths to determine the effects of solar UV exclusion during cultivation on the physiology and production of curcuminoids. To broaden the biochemical characterization, the activities of L-phenylalanine ammonia-lyase (PAL) and peroxidase (POD), as well as total phenol content (TP) and polyamines (PAs), were considered. We discovered that the curcumin and DMC content remain unaltered, however BDMC was higher in the turmeric under 50\% shading, comparing with UV exclusion. Although the total curcuminoid content remain unaltered, $\mathrm{UV}$ exclusion led to higher $\mathrm{CO}_{2}$ net assimilation, biomass production and consequently, a notable $21 \%$ increase of total curcuminoid yield, compared with the best result obtained by standard shading; thus UV exclusion improved total curcuminoid yield and this result may be important to the development of $C$. longa with high rhizome yield and with high curcuminoid content. This finding underlines the importance of selective wavelengths in $C$. longa cultivation.
\end{abstract}

(c) 2016 Elsevier B.V. All rights reserved.

\section{Introduction}

Curcuma longa L. (Zingiberaceae), also known as turmeric, is a monocot species widely cultivated in the tropics. It is an important source of curcuminoids, comprising curcumin [(1E,6E)-1,7-bis-(4hydroxy-3-methoxy-phenyl)-1,6-heptadien-3,5-dione; CAS number: 458-37-7] and two related compounds, demethoxycurcumin (DMC) and bisdemethoxycurcumin (BDMC) (Kulkarni et al., 2012; Payton et al., 2007). Curcumin has attracted considerable interest in recent years due to its high medicinal potential. It has been widely studied for its anti-inflammatory, anti-angiogenic, anti-oxidant, wound healing and anti-cancer effects (Maheshwari et al., 2006), which inhibit cancer cell survival and proliferation and induce apoptosis without promoting the development of side effects (Salem et al., 2014).

There is a great need to further increase the productivity of turmeric, because of its ever-increasing demand in both food and pharmaceutical industries (Singh et al., 2012). Moreover the global curcumin market is expected to witness high growth on account of

\footnotetext{
* Corresponding author.

E-mail address: gpplima@ibb.unesp.br (G.P.P. Lima).
}

its increasing demand in end-use industries (Grand View Research, 2015).

Although India has a monopoly in supplying of turmeric to the world (Angles et al., 2011), an ever-increasing requirement for curcumin can provide an interesting market to improve the development of this crop production in other countries. Notably, turmeric shows significant variations in plant productivity, both among varieties and in plants grown under different agro-climatic conditions. Farming techniques that increase the curcuminoids' content in turmeric can contribute to improving the production of this crop.

The influence of environmental stress factors on the chemical composition and nutritional value of crop plants is an important research topic. Sunlight damages the photosynthetic machinery, primarily photosystem II (PSII), leading to photoinhibition and loss of plant performance, ultimately suppressing photosynthetic $\mathrm{CO}_{2}$ assimilation $(A)$, growth and productivity, whereas ultraviolet (UV) wavelengths $(280-400 \mathrm{~nm})$ are much more efficient photoinhibitors than is photosynthetically active radiation (PAR) (wavelengths 400-700 nm) (Takahashi et al., 2010).

Additionally, ambient levels of solar UV radiation may represent an environmental stress for plants, leading to an increase in the production of reactive oxygen species (ROS), triggering protective 
effects (Brosche and Strid, 2003) that induce the biosynthesis of UV-B absorbing phenolic compounds (Jansen et al., 1998), as well as changes in antioxidant enzyme activities and polyamines (PAs) content (Frohnmeyer and Staiger, 2003).

PAs have a regulatory role in the structure and functioning of the photosynthetic apparatus during photoadaptation in different light environments (Kotzabasis et al., 1999), and there is evidence that PAs play a photoprotective role during exposure of the photosynthetic apparatus to high-light intensity (Sfichi et al., 2004). However, there is no consensus with respect to the effects of UV-B radiation (280-315 nm) on plant polyamine levels, as chronic treatment with low UV-B doses resulted in both increases and decreases in plant polyamine levels (Jansen et al., 2008).

Induction of the enzymes L-phenylalanine ammonia-lyase ([PAL], EC 4.3.1.5) peroxidase ([POD], EC 1.11.1.7) and several other enzymes that take part in many aspects of phenolic compounds metabolic pathway, has been shown to occur under UV-B radiation exposure, with a consequent accumulation of phenolic acids and flavonoids (Lavola et al., 2000). In addition, the initial substrates in the curcuminoids synthesis in C. longa (cinnamoyl-CoA, $p$-coumaroyl-CoA or feruloil-CoA) are synthesized from phenylalanine by PAL activity (Katsuyama et al., 2009). Curcumin is synthetized in the leaves and then translocates to the rhizomes (Dixit and Srivastava, 2000a), but the expression levels of enzyme genes involved in curcumin synthesis [diketide-CoA synthase (DCS) and curcumin synthase (CURS)] were higher in the rhizome than in the leaf, in agreement with the higher amounts of curcuminoids in the rhizome than in the leaves (Katsuyama et al., 2009).

Some studies previously reported about the influence of light intensity on the productivity and quality of turmeric (Bhuiyan et al., 2012, Hossain et al., 2009, Padmapriya et al., 2007 and Srikrishnah and Sutharsan, 2015), indicating that $C$. longa has a good curcumin productivity under shade. However, no study is available in the literature about the influence of UV exclusion on the quality of turmeric plants. Thus, in the present paper, we explored the effect of PAR intensity and UV exclusion on the biosynthesis of secondary metabolites, in particular curcuminoids. To broaden the biochemical characterization, the activities of PAL and POD, as well as the total phenol content and PAs were considered.

\section{Materials and methods}

\subsection{Study site and experimental design}

The experiments were conducted in the experimental farm of the School of Agronomy, São Paulo State University - UNESP, Botucatu, São Paulo, located in the municipality of São Manuel, São Paulo $\left(22^{\circ} 46^{\prime} 0,571^{\prime \prime} \mathrm{S}\right.$ and $\left.48^{\circ} 34^{\prime} 11,32^{\prime \prime} \mathrm{W}, 744 \mathrm{~m}\right)$.

The experimental design was completely randomized, with five light conditions and five replicates of eight plants each. The light conditions were as follows: UV exclusion, full sun, 30\%, 50\% and $70 \%$ screen shading.

The soil is classified as Oxisol, sandy phase (Camargo et al., 1987; Santos et al., 2006). In the layer between 0 and $0.20 \mathrm{~m}$ it exhibited the following chemical characteristics: Organic matter $\left(\mathrm{g} \mathrm{dm}^{-3}\right)=12 ; \mathrm{pH}=5,4 ; \mathrm{P}\left(\mathrm{mg} \mathrm{dm}^{-3}\right)=204 ; \mathrm{K}\left(\mathrm{mmol}_{\mathrm{C}} \mathrm{dm}^{-3}\right)=2,5$; $\mathrm{Ca} \quad\left(\mathrm{mmol}_{\mathrm{c}} \mathrm{dm}^{-3}\right)=39 ; \quad \mathrm{Mg} \quad\left(\mathrm{mmol}_{\mathrm{c}} \mathrm{dm}^{-3}\right)=11 ; \quad \mathrm{CTC}=71$ $\left(\mathrm{mmol}_{\mathrm{C}} \mathrm{dm}^{-3}\right) ; \mathrm{V}=76 \%$.

The seed rhizomes of approximately $12 \mathrm{~cm}$ in length were selected and homogenized. Planting was done in September and carried out on plots of $0.4 \mathrm{~m}$ height with the rhizomes spaced $0.5 \mathrm{~m}$ apart and at a depth of $4 \mathrm{~cm}$.

During plant development, necessary weed control and repairs in the crop ridges were carried out manually. The plots were irrigated daily, according to the water demand recorded by ten- siometers, and irrigation was suspended 15 days before harvest. The harvest was made at the end of the plant cycle, 203 days after planting (DAP).

\subsection{Treatments characterization and photosynthetically active radiation (PAR) measurement}

The different light conditions were obtained by protected environments in a high-tunnel structure, $3 \mathrm{~m}$ wide, $1.70 \mathrm{~m}$ high and $22.5 \mathrm{~m}$ long, with different coatings for light exposure control. The coating applied to exclude UV radiations was an anti-UV polyethylene film $(150 \mu \mathrm{m})$ (Trifilme Plastilux, Plastisul, Sapucaia do Sul, Rio Grande do Sul, Brazil), characterized by the exclusion of more than $80 \%$ of UV-B radiation, and the coatings used to control shading levels were black polyethylene mesh with $30 \%, 50 \%$ and $70 \%$ shading.

An infrared gas analyzer (LI-6400, Li-Cor Inc. Lincoln, NE, USA) was used to quantify the photosynthetically active radiation (PAR) and $\mathrm{CO}_{2}$ net assimilation $(A)$ in each light-exposure condition. The measurements were carried out at 09:00 and 11:00 AM on cloudless days, at 62,114, 169 and 201 DAP, with radiation inside the chamber standardized to $1500 \mu \mathrm{mol} \mathrm{m}^{-2} \mathrm{~s}^{-1}$. The mean PAR measured was used to define the amount of radiation present in each treatment: full sun $\left(100 \%\right.$ PAR $\left.=1200 \mu \mathrm{mol} \mathrm{m}^{-2} \mathrm{~s}^{-1}\right)$, $30 \%$ shade $\left(52,5 \%\right.$ PAR $\left.=630 \mu \mathrm{mol} \mathrm{m}^{-2} \mathrm{~s}^{-1}\right), 50 \%$ shade $(41,66 \%$ $\left.\mathrm{PAR}=500 \mu \mathrm{mol} \mathrm{m}^{-2} \mathrm{~s}^{-1}\right), 70 \%$ shade $\left(30 \% \mathrm{PAR}=360 \mu \mathrm{mol} \mathrm{m}^{-2} \mathrm{~s}^{-1}\right)$ and UV exclusion $\left(50,83 \%\right.$ PAR $\left.=610 \mu \mathrm{mol} \mathrm{m}^{-2} \mathrm{~s}^{-1}\right)$.

\subsection{Samples preparations and biomass determination}

Eight plants were harvested (203 DAP), cleaned and the shoots were separated from the rhizomes. Two plants of each replica were frozen in liquid nitrogen and kept in a freezer at $-80^{\circ} \mathrm{C}$. Before each analysis, rhizome and leaf samples were ground in a cryogenic mill (Spex, 6750 freezer/mill, Metuchen, NJ, USA). These samples were used for enzymatic analysis of the phenylalanine ammonia lyase (PAL) activity, peroxidase (POD) activity and total phenolic content (TP). The polyamines (PAs) content (putrescine, spermidine and spermine) was determined for the same samples, after lyophilization.

Six plants of each replica were sliced and dried in a forced air-circulating oven at $65 \pm 5^{\circ} \mathrm{C}$ until the samples reached a constant weight to determine biomass production, expressed per plant. These dried rhizomes were milled to a fine powder, pooled, mixed and used to measure the curcumin content by UHPLC. The water content in the leaves was approximately $63.09 \pm 0.65 \%$ and was $82.84 \pm 0.75 \%$ in the rhizomes for fresh and lyophilized samples.

\subsection{Biochemical analyses}

\subsubsection{Chemicals}

Folin-Ciocalteu's phenol reagent, sodium carbonate, potassium phosphate, methanol, toluene and acetone were obtained from Vetec/Sigma (Sigma Aldrich, Brazil); HPLC grade methanol and HPLC grade acetonitrile was obtained from Tedia (Tedia, Brazil); gallic acid, acetic acid, perchloric acid, proline, dansyl chloride, phenylalanine, $\beta$-mercaptoethanol borate, peroxide, 4-aminoantipyrine, dichlorophenol, curcuminoids and PAs standards, were obtained as their hydrochlorides from Sigma (Sigma Aldrich, Brazil).

\subsubsection{Extraction and estimation of phenylalanine ammonia lyase (PAL) activity}

The activity of PAL was determined according to Peixoto et al. (1999) using $0.1 \mathrm{M}$ borate buffer, $\mathrm{pH} 8.8$ containing $5 \mathrm{mM} \beta$ mercaptoethanol for the extraction. The extracts were added to 
$0.2 \mathrm{M}$ borate buffer, $\mathrm{pH} 8.8$ and the test tubes were maintained at $36^{\circ} \mathrm{C}$ for $5 \mathrm{~min}$ in a water bath, followed by the addition of $0.1 \mathrm{M}$ phenylalanine and then incubated at this temperature for $60 \mathrm{~min}$. Absorbance at $290 \mathrm{~nm}$ was measured in a UV-vis spectrophotometer (Amersham-Pharmacia Biotech Ultrospec-2000) and the results were expressed in abs $\mathrm{min}^{-1} \mathrm{~g}^{-1}$ fresh weight.

\subsubsection{Extraction and estimation of peroxidase (POD) activity}

The POD activity was assessed as described by Lima et al. (1999), in a $0.2 \mathrm{M}$ potassium phosphate buffer, $\mathrm{pH} 6.7$ for the extraction. A $30 \% \mathrm{H}_{2} \mathrm{O}_{2}$ solution was added to the extract, followed by $8 \mathrm{mM}$ of 4 -aminoantipyrine and $14 \mathrm{mM}$ of dichlorophenol solution. The tubes were kept in a water bath at $30^{\circ} \mathrm{C}$ for $5 \mathrm{~min}$, and the samples' absorbance at $505 \mathrm{~nm}$ was measured in a UV-vis spectrophotometer (Amersham-Pharmacia Biotech Ultrospec-2000). The results were expressed in Abs min $^{-1} \mathrm{~g}^{-1}$ fresh weight.

\subsubsection{Extraction and determination of total phenolic content (TP)}

The TP was determined using Folin-Ciocalteu reagents, with analytical grade gallic acid as the standard, according to the procedures described by Singleton and Rossi (1965). Fresh samples were extracted in 50\% acetone and the supernatant was separated, added to deionized water and Folin-Ciocalteu phenol reagents. After $5 \mathrm{~min}, 20 \%$ sodium carbonate was added to the mixture. The mixing solution was allowed to stand for another $60 \mathrm{~min}$ before the absorbance at $725 \mathrm{~nm}$ was measured using a UV-vis spectrophotometer (Amersham-Pharmacia Biotech Ultrospec-2000). The amounts of TP were calculated using a gallic acid calibration curve. The results were expressed as gallic acid equivalents (GAE) $\left(\mathrm{mg} \mathrm{g}^{-1}\right)$ of fresh plant matter.

\subsubsection{Determination of polyamines (PAs) content}

The polyamines putrescine (Put), spermidine (Spd) and spermine (Spm) were extracted and isolated according to the procedure of Flores and Galston (1982) modified by Lima et al. (2008). Briefly, turmeric samples were weighed and homogenized in perchloric acid $(5 \% \mathrm{v} / \mathrm{v})$ for $1 \mathrm{~h}$ at $4{ }^{\circ} \mathrm{C}$. After centrifugation $(8000 \mathrm{~g}, 20 \mathrm{~min}$ at $\left.4{ }^{\circ} \mathrm{C}\right), 4.5 \mathrm{~mol} \mathrm{~L}^{-1} \mathrm{Na}_{2} \mathrm{CO}_{3}$ and $18.5 \mathrm{mmol} \mathrm{L}^{-1}$ dansyl-chloride in acetone was added to the supernatant. The samples were incubated in the dark for 1-h at room temperature. Then, $0.87 \mathrm{~mol} \mathrm{~L}^{-1}$ of proline (99\%) was added, and the samples were maintained at room temperature for $30 \mathrm{~min}$. Toluene was used to extract the dansylated PAs. Finally, sample aliquots were withdrawn and subjected to drying with $\mathrm{N}_{2}$ and resuspended in $3 \mathrm{~mL}$ of HPLC grade acetonitrile. Determination of the PAs content was performed according Dadáková et al. (2009). The samples $(20 \mu \mathrm{L})$ were injected into a UHPLC system (Ultimate 3000 BioRS, DionexThermo Fisher Scientific Inc., USA) equipped with a diode array detector set at $225-300 \mathrm{~nm}$, run at a flow rate of $0.7 \mathrm{~mL} \mathrm{~min}^{-1}$ using an Ace 5C18 (Advanced Chromatography Technologies, UK) column ( $5 \mu \mathrm{m}, 25 \mathrm{~cm} \times 4.6 \mathrm{~mm})$.

The chromatographic run gradient scheme performed was established with different proportions of (A) acetonitrile 100\% and (B) acetonitrile $50 \%$ as follows: $0-4 \mathrm{~min}, 40 \% \mathrm{~A}+60 \% \mathrm{~B}$; $4-8 \mathrm{~min}$, $60 \%$ A + 40\% B; 8-12 min, 65\% A + 35\% B; $12-15 \min , 85 \%$ A + 15\% B; 15-21 min, 95\% A+5\% B; 21-22 min, 85\% A+15\% B; 22 min, 75\% $A+25 \% B$.

\subsubsection{Determination of curcuminoids content}

The curcuminoid extraction and UHPLC determination of bisdemethoxy-curcumin (BDMC), demethoxy-curcumin (DMC) and curcumin was carried out according to a procedure derived by $\mathrm{He}$ et al. (1998), with some modifications.

Dried turmeric was ground in a mill and $0.1 \mathrm{~g}$ of this powder was refluxed with $20 \mathrm{~mL}$ of methanol for $1 \mathrm{~h}$; then, $1 \mathrm{~mL}$ was diluted with methanol in a volumetric flask $(10 \mathrm{~mL})$. All samples were filtered through $0.22 \mu \mathrm{m}$ membrane filters before the injections. The injection volume was $20 \mu \mathrm{L}$ (full loop) A UHPLC system (Ultimate 3000 BioRS, Dionex-Thermo Fisher Scientific Inc., USA) equipped with a diode array detector, and an Ace 5C18 (Advanced Chromatography Technologies, UK) column $(5 \mu \mathrm{m}, 25 \mathrm{~cm} \times 4.6 \mathrm{~mm})$ was used for the curcuminoids analysis at $48^{\circ} \mathrm{C}$. The gradient profile of the mobile phase was composed of $(A)$ water $(0.25 \%$ acetic acid $)$ and (B) acetonitrile, as follows: 0-17 $\mathrm{min}, 40-60 \% \mathrm{~B} ; 17-32 \mathrm{~min}$, $60-85 \%$ B; 32-38 min, 85\% B; 38-40 min, 85-40\% B; 40-45 min, 40\% $\mathrm{B}$; the flow rate was $0.5 \mathrm{~mL} \mathrm{~min}^{-1}$. The curcuminoids peaks were identified by the retention times and the injection tests with the standards (curcumin, demethoxy-curcumin and bisdemethoxycurcumin).

The final yield of curcuminoids (curumin, DMC and BDMC) and total curcuminoids was determined by calculating the content $\left(\mathrm{mgg}^{-1}\right)$ and the accumulated biomass $(\mathrm{g})$ in each plot (Curcuminoids Yield $(\mathrm{mg})=$ content $\left(\mathrm{mg} \mathrm{g}^{-1}\right) \times$ biomass $(\mathrm{g})$ ). This curcuminoids yield was expressed in $\mathrm{mg}$ and converted to $\mathrm{g}$.

\subsection{Statistical analysis}

All of the data are presented in triplicate $(n=3)$. The experimental results were expressed as the mean value (mean $\pm \mathrm{SE}$ ). The data were analyzed using the Assistat statistical program (version 7.7 beta (pt)) and SigmaPlot package (version 12.0). Significant differences between the samples $(P<0.05)$ were evaluated by analysis of variance (ANOVA) followed by Tukey test and Pearson correlation (R).

\section{Results and discussion}

\subsection{PAL activity and total phenol content (TP)}

The PAL activity was studied in C. longa leaves and rhizomes cultivated in the shading range and UV exclusion. The lowest PAL activity was found in leaves grown under $70 \%$ shading and was comparable to that of plants under UV exclusion. The leaf TP followed the PAL activity thus 70\% shading and UV exclusion induced the lowest values (Table 1). These findings are in agreement with the protecting role of phenolics against ROS, once they appear in lower amounts in less-stressed plants, and this low TP is likely in response to the low PAL activities observed in this study once they show a strong correlation $(R=0.86)$ (Table 2$)$. Regarding the rhizomes, shading did not influence the PAL enzymatic activity levels in the rhizomes (Table 1), and under UV exclusion it was only slightly lower in comparison to plants exposed to full sun, representing the condition correlated with the highest activity. The dependence of PAL catalytic activity on the UV-radiation level exposure was previously reported (Lavola et al., 2000). PAL is believed to have a role in some polyphenol biosynthesis (Cheng et al., 2001). Although PAL does not synthesize only phenols from phenylalanine, an increase in its enzymatic activity may be correlated with higher phenol content, as a protection against UV-induced stress. However, in the rhizomes, a negative correlation between PAL activity and TP was observed $(\mathrm{R}=-0.74)$ (Table 2$)$, and no difference of the total phenol content was found between anti-UV and full sun-grown plants (Table 1).

\subsection{POD activity and PAs content}

Among all of the treatments, the absence of UV radiation led to the lowest POD activity in the rhizomes, while POD activity increased with light exposure (Table 1). Similar results were found in the leaves, with the highest POD activity measured in plants grown under full sun and 50\% shading, and the lowest enzymatic 
Table 1

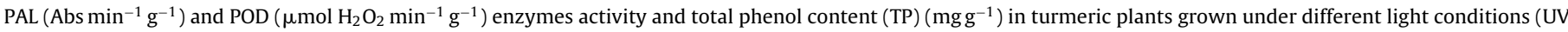
exclusion, $70 \%, 50 \%, 30 \%$ shading and full sun).

\begin{tabular}{|c|c|c|c|c|c|}
\hline & UV exclusion & $70 \%$ shade & $50 \%$ shade & $30 \%$ shade & Full sun \\
\hline \multicolumn{6}{|c|}{ Leaves } \\
\hline PAL & $0.08 \pm 0.01^{\mathrm{b}}$ & $0.08 \pm 0.01^{\mathrm{b}}$ & $0.10 \pm 0.01^{\mathrm{ab}}$ & $0.13 \pm 0.03^{\mathrm{a}}$ & $0.13 \pm 0.02^{\mathrm{a}}$ \\
\hline POD & $7.04 \pm 0.76^{a b}$ & $7.18 \pm 1.26^{\mathrm{ab}}$ & $7.81 \pm 1.67^{\mathrm{a}}$ & $5.55 \pm 0.85^{\mathrm{b}}$ & $7.95 \pm 0.59^{a}$ \\
\hline $\mathrm{TP}$ & $12.24 \pm 1.31^{\mathrm{c}}$ & $12.76 \pm 0.37^{b c}$ & $14.74 \pm 0.85^{\mathrm{a}}$ & $14.43 \pm 1.40^{\mathrm{ab}}$ & $14.67 \pm 0.37^{a}$ \\
\hline \multicolumn{6}{|c|}{ Rhizomes } \\
\hline PAL & $0.17 \pm 0.01^{\mathrm{ab}}$ & $0.13 \pm 0.02^{\mathrm{b}}$ & $0.15 \pm 0.04^{b}$ & $0.14 \pm 0.02^{\mathrm{b}}$ & $0.20 \pm 0.02^{\mathrm{a}}$ \\
\hline POD & $1.80 \pm 0.54^{\mathrm{b}}$ & $2.91 \pm 0.99^{\mathrm{ab}}$ & $2.86 \pm 0.72^{\mathrm{ab}}$ & $3.00 \pm 0.62^{\mathrm{ab}}$ & $3.71 \pm 0.83^{a}$ \\
\hline $\mathrm{TP}$ & $35.51 \pm 3.07^{c}$ & $41.28 \pm 2.21^{\mathrm{ab}}$ & $36.63 \pm 1.96^{\mathrm{abc}}$ & $41.56 \pm 4.54^{\mathrm{a}}$ & $35.73 \pm 2.02^{b c}$ \\
\hline
\end{tabular}

Data are the means of five replicates. Data with the same letter within each column are not significantly different at the $5 \%$ level, based on the Tukey's test.

Table 2

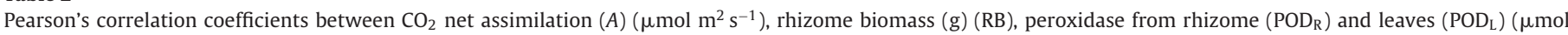

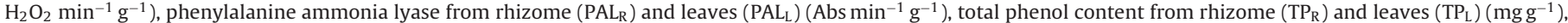

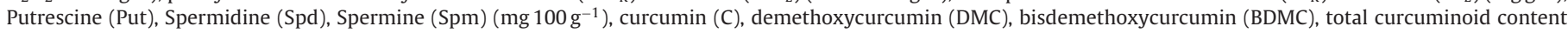

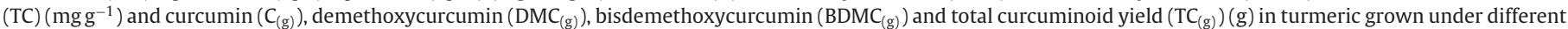
light conditions (UV exclusion, 70\%, 50\%, 30\% shading and full sun).

\begin{tabular}{|c|c|c|c|c|c|c|c|c|c|c|c|c|c|c|c|c|c|c|}
\hline & $\mathrm{RB}$ & $\begin{array}{l}\text { POD } \\
\mathrm{R}\end{array}$ & $\begin{array}{l}\text { POD } \\
\mathrm{L}\end{array}$ & $\begin{array}{l}\text { PAL } \\
\mathrm{R}\end{array}$ & $\begin{array}{l}\text { PAL } \\
\mathrm{L}\end{array}$ & $\begin{array}{l}\mathrm{TP} \\
\mathrm{R}\end{array}$ & $\begin{array}{l}\mathrm{TP} \\
\mathrm{L}\end{array}$ & Put & Spd & Spm & C & DMC & BDMC & $\mathrm{TC}$ & $\begin{array}{l}C \\
(\mathrm{~g})\end{array}$ & $\begin{array}{l}\text { DMC } \\
(\mathrm{g})\end{array}$ & $\begin{array}{l}\text { BDMC } \\
(\mathrm{g})\end{array}$ & $\begin{array}{l}\text { TC } \\
(\mathrm{g})\end{array}$ \\
\hline A & $0.91^{*}$ & $-0.88^{* *}$ & -0.09 & 0.17 & -0.49 & -0.49 & -0.66 & $0.96^{*}$ & -0.08 & -0.47 & 0.65 & -0.53 & -0.73 & -0.29 & $0.91^{*}$ & 0.66 & 0.59 & \\
\hline $\mathrm{RB}$ & & $-0.93^{* *}$ & -0.09 & -0.08 & -0.51 & -0.44 & -0.50 & $0.95^{*}$ & 0.13 & -0.68 & 0.70 & -0.25 & -0.44 & -0.02 & $0.99^{* *}$ & $0.89^{*}$ & 0.86 & $0.96^{* *}$ \\
\hline $\mathrm{POD}_{\mathrm{R}}$ & & & 0.22 & 0.31 & 0.72 & 0.17 & 0.75 & $-0.86^{*}$ & 0.20 & 0.82 & -0.64 & 0.21 & 0.46 & 0.05 & $-0.91^{*}$ & -0.81 & -0.75 & $-0.87^{*}$ \\
\hline $\mathrm{POD}_{\mathrm{L}}$ & & & & 0.44 & -0.20 & -0.70 & 0.10 & 0.12 & -0.06 & 0.13 & 0.61 & 0.49 & 0.43 & 0.67 & 0.06 & 0.14 & 0.13 & 0.09 \\
\hline $\mathrm{PAL}_{\mathrm{R}}$ & & & & & 0.45 & -0.74 & 0.27 & 0.16 & 0.26 & 0.82 & 0.10 & -0.50 & -0.39 & -0.34 & -0.03 & -0.29 & -0.29 & -0.16 \\
\hline $\mathrm{PAL}_{\mathrm{L}}$ & & & & & & 0.04 & 0.86 & -0.53 & 0.68 & 0.82 & -0.73 & -0.31 & 0.00 & -0.42 & -0.59 & -0.61 & -0.52 & -0.59 \\
\hline $\mathrm{TP}_{\mathrm{R}}$ & & & & & & & -0.04 & -0.63 & -0.30 & -0.13 & -0.70 & 0.14 & 0.19 & -0.15 & -0.52 & -0.39 & -0.38 & -0.47 \\
\hline $\mathrm{TP}_{\mathrm{L}}$ & & & & & & & & -0.55 & 0.79 & 0.61 & -0.51 & 0.19 & 0.47 & 0.10 & -0.53 & -0.36 & -0.24 & -0.43 \\
\hline Put & & & & & & & & & 0.04 & -0.54 & 0.80 & -0.31 & -0.52 & -0.04 & $0.98^{* *}$ & 0.81 & 0.76 & $0.91^{* *}$ \\
\hline Spd & & & & & & & & & & 0.26 & -0.17 & -0.08 & 0.12 & -0.04 & 0.07 & 0.17 & 0.28 & 0.15 \\
\hline Spm & & & & & & & & & & & -0.56 & -0.34 & -0.09 & -0.41 & -0.69 & -0.82 & -0.79 & -0.76 \\
\hline C & & & & & & & & & & & & 0.22 & -0.02 & 0.49 & 0.80 & 0.78 & 0.73 & 0.80 \\
\hline DMC & & & & & & & & & & & & & $0.95^{*}$ & $0.95^{*}$ & -0.18 & 0.21 & 0.25 & 0.02 \\
\hline BDMC & & & & & & & & & & & & & & 0.86 & -0.39 & 0 & 0.07 & -0.19 \\
\hline TC & & & & & & & & & & & & & & & 0.07 & 0.42 & 0.44 & 0.25 \\
\hline$C(\mathrm{~g})$ & & & & & & & & & & & & & & & & $0.91^{*}$ & $0.87^{*}$ & $0.97^{* *}$ \\
\hline DMC (g) & & & & & & & & & & & & & & & & & $0.99^{*}$ & $0.98^{*}$ \\
\hline $\operatorname{BDMC}(\mathrm{g})$ & & & & & & & & & & & & & & & & & & $0.96^{* *}$ \\
\hline
\end{tabular}

L-leaves, R-rhizome.

${ }^{*} P<0.05$.

${ }^{* *} P<0.01$.

Table 3

$\mathrm{CO}_{2}$ net assimilation $(A)\left(\mu \mathrm{mol} \mathrm{m} \mathrm{m}^{-1}\right)$ and rhizome biomass $(\mathrm{g})$ in turmeric rhizomes grown under different light conditions (UV exclusion, $70 \%, 50 \%, 30 \%$ shading and full sun).

\begin{tabular}{lrl}
\hline Treatments & \multicolumn{1}{l}{ Biomass } \\
\hline UV exclusion & $10.62 \pm 0.80^{\mathrm{a}}$ & $797.03 \pm 174.04^{\mathrm{a}}$ \\
$70 \%$ shade & $7.13 \pm 2.05^{\mathrm{a}}$ & $476.83 \pm 32.03^{\mathrm{cd}}$ \\
$50 \%$ shade & $7.57 \pm 2.51^{\mathrm{a}}$ & $628.42 \pm 13.07^{\mathrm{b}}$ \\
$30 \%$ shade & $7.55 \pm 3.03^{\mathrm{a}}$ & $540.42 \pm 17.37^{\mathrm{bc}}$ \\
Full sun & $7.24 \pm 0.52^{\mathrm{a}}$ & $436.14 \pm 46.68^{\mathrm{d}}$ \\
\hline
\end{tabular}

Data are the means of five replicates. Data with the same letter within each column are not significantly different at the $5 \%$ level, based on the Tukey's test.

activity was found at $30 \%$ shading (Table 1 ). It has been reported that the exclusion of solar UV-B radiation in oilseed rape (Brassica napus L.) results in the lowering of POD enzyme activity (Zhu and Yang, 2015). In this research, we observed that POD activity is higher in the leaves and rhizomes of plants cultivated under high PAR intensities and lower under anti UV conditions, excluding the leaves of the plants grown under 30\% shade. In addition we found a strong negative correlation between POD activity and $A$ $\left(\mathrm{R}=-0.88^{* *}\right)$ as well as between POD activity and rhizome biomass $\left(\mathrm{R}=-0.93^{* *}\right)$ (Table 2$)$. These correlations indicate that high PAR is a stressing factor, thus leading to increased POD activity, decreased $A$ and biomass production (Table 3 ).
The highest POD activity found for full-sun cultivation may be due to the oxidative enzymes of the PAs, such as diamine oxidase (DAO) and polyamine oxidase (PAO), which may have increased activity during some light-induced stress situations, as described by Goyal and Asthir (2010). These researchers reported an increase in the PAO and DAO activities leading to a decline in the levels of endogenous PAs in wheat genotypes under high-temperature stress. The peroxides are formed during the catabolism of PAs, and to prevent the oxidizing action of these compounds, an increase in the POD activity in turmeric rhizomes and leaves may have occurred considering that hydrogen peroxide is a substrate of POD. Furthermore, a very strong correlation between Spm and POD $(\mathrm{R}=0.82)$ and a very strong negative correlation between Put and POD $\left(R=-0.86^{*}\right)$ was detected (Table 2$)$ and high Spm levels and low Put levels in plants' rhizomes exposed to full sun (Fig. 1) were observed in the present study.

The treatments did not influence the Spd content, and shade levels did not influenced Put, however, the exclusion of UV radiation led to increased Put concentration in rhizomes (Fig. 1) The Put/Spm is high in plants under UV radiation exclusion, and this ratio is the opposite of the ratio in the plants exposed to full sun (Fig. 1). According to Sfichi et al. (2004), UV-B radiation induces a decrease in the thylakoid-associated Put and an increase in Spm. The reduction of the Put/Spm ratio leads to the increase of the light-harvesting complex II size per active reaction center and, 


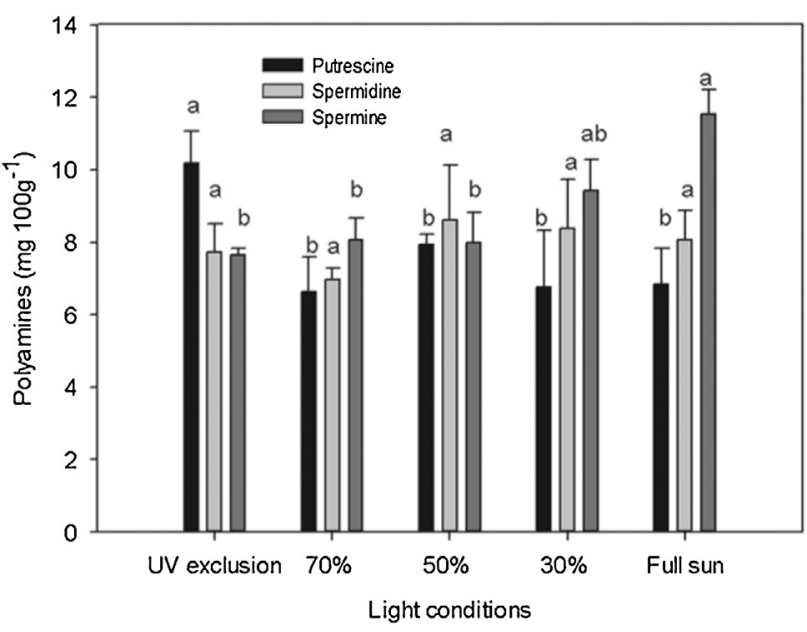

Fig. 1. PAs content $\left(\mathrm{mg} 100 \mathrm{~g}^{-1}\right)$ in rhizome of turmeric grown under different light conditions (UV exclusion, 70\%, 50\%, 30\% shading and full sun). Means followed by the same letters indicate no significant difference at $P<0.05$ level between the light conditions.

consequently, the amplification of the UV-B effects on the photosynthetic apparatus, suppressing photosynthetic $\mathrm{CO}_{2}$ assimilation and biomass production (Takahashi et al., 2010). A very strong correlation between $A$ and Put content $\left(R=0,96^{*}\right)$ and between Put and rhizome biomass $\left(\mathrm{R}=0.95^{*}\right)$ (Table 2 ), as well as suppression of photosynthetic $\mathrm{CO}_{2}$ assimilation and biomass production was observed in this study (Table 3 ).

The higher putrescine content in C. longa grown in anti-UV may be due to the protective effect of this diamine on the photosynthetic apparatus such as have been described in many studies, including stress (Demetriou et al., 2007). According to Czerpak et al. (2003) in chloroplasts this substance may stimulate the photosynthetic process in dark and light phases, and in turmeric the lower UV radiation level under polyethylene could maintain elevate ratio Put/Spm, with its protective effect, inducing higher photosynthetic rate and consequently superior production of biomass.

PAs produced in the leaves might be translocated to rhizome by xylem or phloem (Friedman et al., 1986). PAs have been localized in the vacuoles, chloroplasts, mitochondria and in thylakoid membranes (Borrell et al., 1995; Martin-Tanguy, 2001). Studies also show that overall depletion of polyamine pools may affect the roots' growth (Couée et al., 2004). Thus, the higher content of polyamines observed in turmeric rhizomes might be in consequence of photosynthesis, affecting the growth and thereby increasing biomass. However, we emphasize that more studies should be conducted to conclude that the quantity or quality of light can alter the content of the rhizomes polyamines.

\subsection{Biomass and photosynthetic $\mathrm{CO}_{2}$ assimilation}

When considering all of photosynthetic assimilation of $\mathrm{CO}_{2}$ data during cultivation, there was no statistical difference between treatments (Table 3). However, the correlation between the assimilation and biomass production is very strong $\left(\mathrm{R}=0.91^{*}\right)$ (Table 2$)$. Biomass production decreased as a function of PAR intensity, except for $70 \%$ shading (Table 3, Fig. 2). These results are in agreement with Bhuiyan et al. (2012), reporting about the growth and development of turmeric and ginger under full sunlight and four agro-forestry systems with different\% of PAR (from 25 to $30 \%$ PAR to 70 to $80 \%$ PAR). According to Bhuiyan and colleagues, the growth parameters and yield gradually decreased with the increase of light intensity.
The impacts of light quantity and quality in plants have been studied. According to Stapleton (1992), auxin inactivation is one of the detailed mechanistic information available for UV-B responses. Morphogenic responses include inhibition of hypocotyl and stem elongation, leaf curling, leaf thickening and increased axillary branching and the root system. Moreover, some UV-B induced flavonoid can block polar auxin transport, and as a consequence, affect plant architecture and productivity (Jansen, 2002).

In this study, we found the highest biomass production at $50 \%$ shading (Fig. 2). This finding was previously observed in a study by Srikrishnah and Sutharsan (2015), in which the leaf area, biomass and yield were significantly higher in a growing condition of $50 \%$ shade. The authors concluded that the decrease of the growth in plants grown in an open field was attributable to the destruction of the photosynthetic pigments due to excess light, and the lower growth parameters under $70 \%$ shading was due to the insufficient amount of solar radiation received by the plants for optimum photosynthesis.

Finally, plants grown under UV protection stand out in terms of rhizome biomass production, with respect to the other treatments, leading to an impressive $21 \%$ higher production with respect to the best result obtained by $50 \%$ shading (Fig. 2 ). Thus, we can assume that plants grown under full sunlight showed some degree of UV morphogenic responses compared with plants grown under UV protection by inactivating or blocking the auxin transport. This result highlights the importance of the selective protection to improve plant productivity.

\subsection{Curcuminoids}

Note that the individualization of the light exposure conditions for obtaining the highest curcumin content, as well as for the highest biomass production, represents an interesting task for curcumin producers, as curcumin yield depends on both of these aspects. In the present study, UV exclusion in C. longa did not affect the curcumin and DMC content in the rhizome, showing similar results when the plants were grown under full sun and in different shadings. A high BDMC content was found in rhizomes from the plants under 50\% shading, although does not differ from other shading levels, and the lowest content was found in the UV-protected plants (Table 3). We also found a very strong correlation between BDMC content and DMC content $\left(\mathrm{R}=0.95^{*}\right)$ and a strong negative correlation with $A(\mathrm{R}=-0.73)$. These correlations may indicate that increases in $A$ imply the decrease of DMC and BDMC. Differently, a moderate correlation between curcumin content and $A(\mathrm{R}=0.65)$ was observed (Table 2).

Some studies indicated that turmeric has high curcumin content and biomass production under shading. Padmapriya et al. (2007) found that plants cultivated under shading (25-30\%) in Coimbatore, India, showed an increase in both the total phenol and curcumin content, besides having registered the highest biomass yield. In Okinawa, Japan, shoot biomass and yield significantly depended on shading, with a maximum production at $27 \%$ shading, and the curcumin content increased when shading was between $41 \%$ and $27 \%$, but decreased when plants were grown under $52 \%$ shading, displaying an antagonistic effect on curcumin accumulation (Hossain et al., 2009). Therefore, the light required for increasing the yield and quality of turmeric cultivation varies with the irradiance level in each place, as well as with agro-climatic conditions.

Curcumin content presented a positive correlation with biomass production ( $R=0.74)$ (Table 2 ) and this correlation may be explained by the dependence of curcumin on the photosynthetic capacity of leaves, then on its translocation and accumulation in the rhizomes (Dixit and Srivastava, 2000a). Furthermore, the amount of photosynthate produced by the leaves and the fraction translocated 

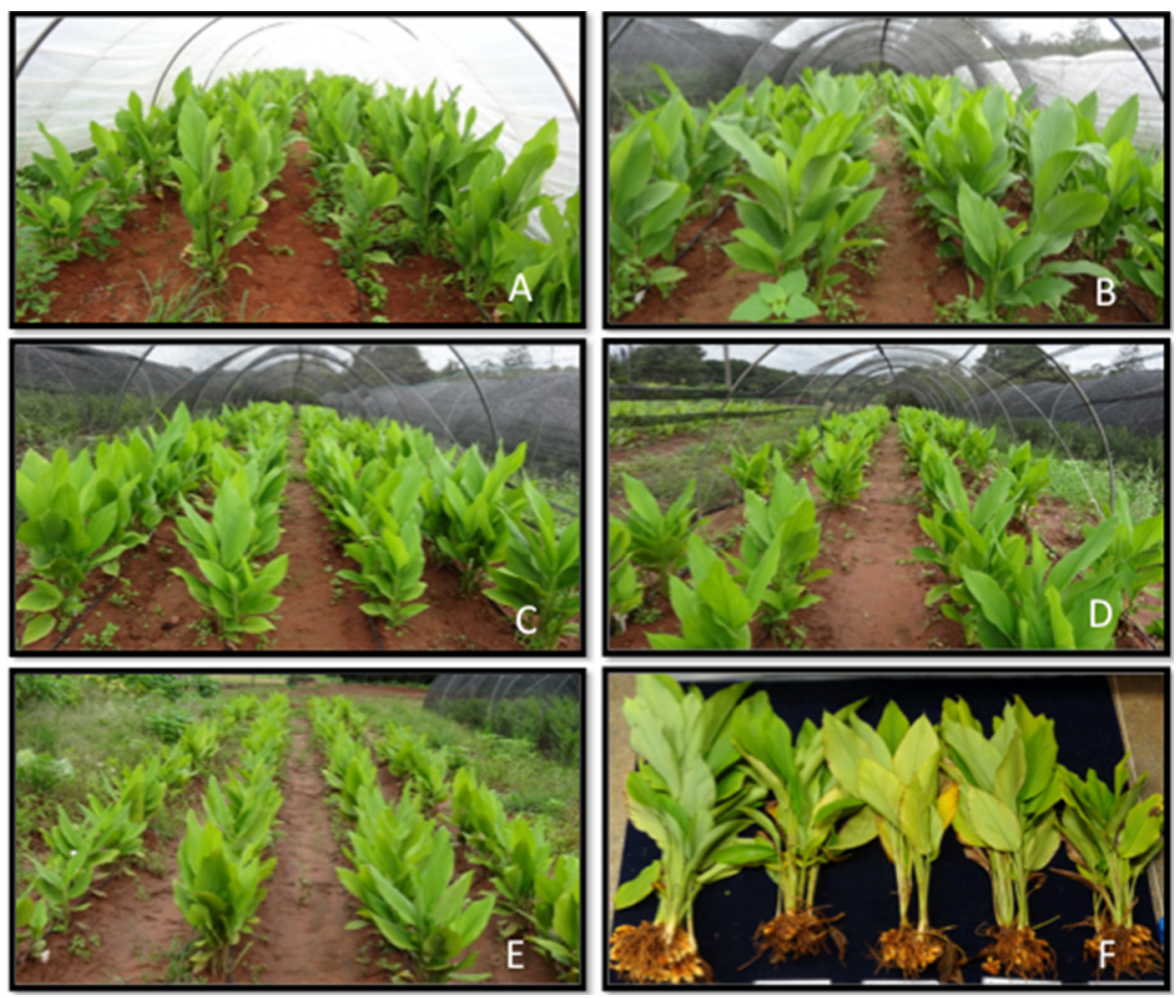

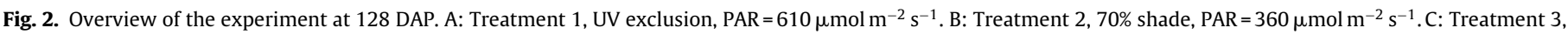

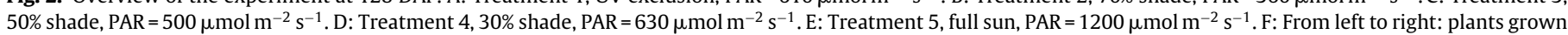
under UV exclusion, $70 \%, 50 \%, 30 \%$ shading and full sun.

Table 4

Demethoxycurcumin (DMC), bisdemethoxycurcumin (BDMC), curcumin and total curcuminoid content $\left(\mathrm{mg} \mathrm{g}^{-1}\right)$ in turmeric rhizomes grown under different light conditions (UV exclusion, 70\%, 50\%, 30\% shading and full sun).

\begin{tabular}{lllrl}
\hline Treatments & DMC & BDMC & \multicolumn{1}{l}{ Curcumin } & Total Curcuminoid \\
\hline Anti-UV & $4.55 \pm 0.26^{\mathrm{a}}$ & $6.55 \pm 0.12^{\mathrm{b}}$ & $10.66 \pm 0.03^{\mathrm{a}}$ & $21.76 \pm 0.29^{\mathrm{a}}$ \\
$70 \%$ shade & $5.50 \pm 0.83^{\mathrm{a}}$ & $8.13 \pm 0.38^{\mathrm{ab}}$ & $9.84 \pm 0.09^{\mathrm{a}}$ & $23.47 \pm 0.92^{\mathrm{a}}$ \\
$50 \%$ shade & $5.70 \pm 0.53^{\mathrm{a}}$ & $8.64 \pm 0.75^{\mathrm{a}}$ & $10.29 \pm 0.56^{\mathrm{a}}$ & $24.63 \pm 1.08^{\mathrm{a}}$ \\
$30 \%$ shade & $4.63 \pm 0.74^{\mathrm{a}}$ & $7.24 \pm 1.45^{\mathrm{ab}}$ & $8.95 \pm 1.34^{\mathrm{a}}$ & $20.82 \pm 2.11^{\mathrm{a}}$ \\
Full sun & $4.82 \pm 0.64^{\mathrm{a}}$ & $7.52 \pm 0.39^{\mathrm{ab}}$ & $9.68 \pm 0.56^{\mathrm{a}}$ & $22.01 \pm 0.93^{\mathrm{a}}$ \\
\hline
\end{tabular}

Data are the means of five replicates. Data with the same letter within each column are not significantly different at the $5 \%$ level, based on the Tukey's test.

to the rhizome will greatly influence the rhizome size, yield and the curcuminoids accumulation. Therefore, the fraction of photoassimilates accumulated by rhizomes (Dixit and Srivastava, 2000b) and the subsequent local biosynthesis (Katsuyama et al., 2009) are the factors controlling secondary metabolite accumulation.

Although the PAR intensity and UV exclusion did not change the curcuminoid content (Table 4), an improvement of $21 \%$ higher total curcuminoid yield (Fig. 3) was observed, comparing with the best result obtained with standard shading and $45 \%$ higher total curcuminoid yield comparing with full sun plants. As reported in this study, we found a strong correlation between $A$ and biomass and between them and the curcumin yield respectively $\left(R=0.91^{*} / R=0.99\right)$, DMC $(R=0.658 / R=0.90)$, $\operatorname{BDMC}(\mathrm{R}=0.59 / \mathrm{R}=0.85)$ and total curcuminoids $\left(\mathrm{R}=0.79 / \mathrm{R}=0.96^{*}\right)$ (Table 2).

These results represent a correlation among different processes, such as curcumin biosynthesis, photosynthetic performances, plant growth and rhizome biomass production, considering that $\mathrm{CO}_{2}$ assimilation and biomass production determined during the growth were higher in plants under UV exclusion (Table 3 ).

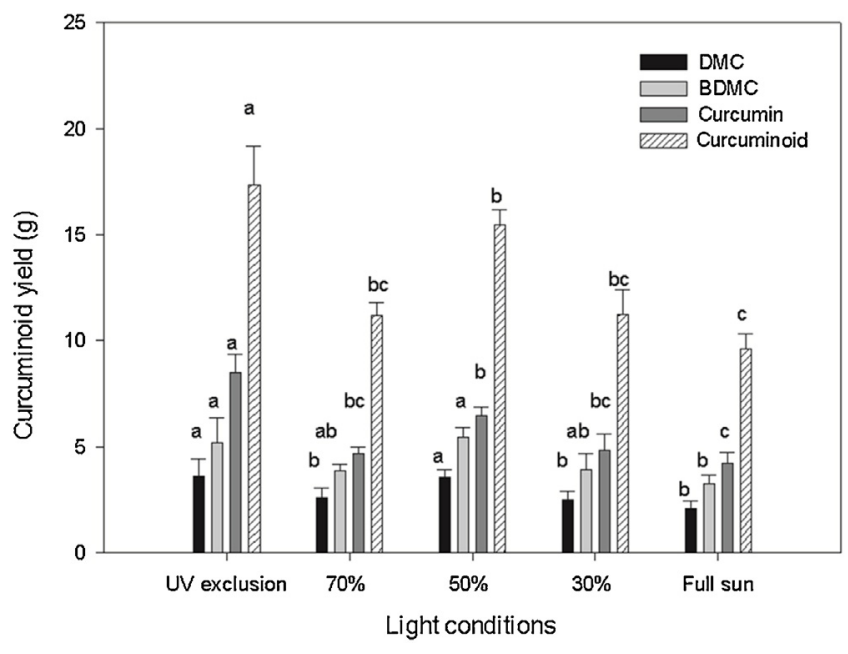

Fig. 3. Demethoxycurcumin (DMC), bisdemethoxycurcumin (BDMC), curcumin and total curcuminoids $(\mathrm{g})$ yield obtainable from rhizomes of turmeric plants grown under different light conditions (UV exclusion, 70\%, 50\%, 30\% shading and full sun). Means followed by the same letters indicate no significant difference at $P<0.05$ level between the light conditions.

\section{Conclusions}

The effects of light exposure and UV exclusion altered the physiology and production of the secondary metabolites in the leaves and rhizomes of $C$. longa. The total phenol content, POD and PAL activity increased with light exposure and decreased under UV exclusion. The content of Spm is higher in the rhizomes of plants exposed to full sun, and the Put levels are higher under UV exclusion. The curcumin and DMC contents ( $\mathrm{mg} \mathrm{g}^{-1}$ ) were unaffected by different light exposures and by UV exclusion, which provided the lowest 
BDMC content, although the plants cultivated under UV exclusion showed a higher ratio of total curcumin over total curcuminoids with respect to other light exposures. Notably, in the UV-protected plants, an increase in the $\mathrm{CO}_{2}$ net assimilation, biomass production, curcumin and curcuminoid yield $(\mathrm{g})$ was evidenced. Based on these results, we conclude that full sun light is a stressful environment for C. longa cultivation and the UV-exclusion provided by the anti-UV polyethylene film during the plants' growth led to improvements in terms of total curcuminoid yield.

\section{Acknowledgements}

The authors acknowledge the support by Coordenação de Aperfeiçoamento de Pessoal de Nivel Superior (CAPES - Brazil; 99999.010436/2014-06), Conselho Nacional de Desenvolvimento Científico e Tecnológico (CNPq - Brazil; 478372/2013-2 and 306151/2012-0) and São Paulo Research Fundation (FAPESP Brazil; 2013/05644-3).

\section{References}

Angles, S., Sundar, A., Chinnadurai, M., 2011. Impact of globalization on production and export of turmeric in India-an economic analysis. Agric. Econ. Res. Rev. 24, 301-308.

Bhuiyan, M.M.R., Roy, S., Sharma, P.C.D., Rashid, M.H.A., Bala, P., 2012. Impact of multistoreyed agro-forestry systems on growth and yield of turmeric and ginger at Mymensingh, Bangladesh. ESci J. Crop Prod. 1, 19-23.

Borrell, A., Culianez-Macia, F.A., Altabella, T., Besford, R.T., Flores, D., Tiburcio, A.F 1995. Arginine decarboxylase is localized in chloroplasts. Plant Physiol. 109, $771-776$.

Brosche, M., Strid, A., 2003. Molecular events following perception of ultraviolet-B radiation by plants. Physiol. Plant. 117, 1-10, http://dx.doi.org/10.1034/j.13993054.2003.1170101.x.

Camargo, M.N., Klamt, E., Kauffman, J.H., 1987. Classificação de solos usada em levantamentos pedológicos no Brasil. Boletim Inf. Soc. Bras. Ciênc. Solo 12, $11-33$

Cheng, S.H., Sheen, J., Gerrish, C., Bolwell, G.P., 2001. Molecular identification of phenylalanine ammonia-lyase as a substrate of a specific constitutively active Arabidopsis CDPK expressed in maize protoplasts. FEBS Lett. 503, 185-188, http://dx.doi.org/10.1016/S0014-5793(01)02732-6.

Couée, I., Hummel, I., Sulmon, C., Gwenola, G., et El Amrani, A., 2004. Involvement of polyamines in root development. Plant Cell Tissue Organ Cult. 76, 1-10.

Czerpak, R., Bajguz, A., Piotrowska, A., Dobrogowska, R., Matejczyk, M., Wieslawski, W., 2003. Biochemical activity of di-and polyamines in the green alga Chlorella vulgaris Beijerinck (Chlorophyceae). Acta Soc. Bot. Pol. 72, 19-24.

Dadáková, E., Kř́ižek, M., Pelikánová, T., 2009. Determination of biogenic amines in foods using ultra-performance liquid chromatography (UPLC). Food Chem. 116, 365-370, http://dx.doi.org/10.1016/j.foodchem.2009.02.018.

Demetriou, G., Neonaki, C., Navakoudis, E., Kotzabasis, K., 2007. Salt stress impact on the molecular structure and function of the photosynthetic apparatus-the protective role of polyamines. Biochim. Biophys. Acta 1767, 272-280, http:// dx.doi.org/10.1016/j.bbabio.2007.02.020.

Dixit, D., Srivastava, N.K., 2000a. Distribution of photosynthetically fixed 14CO2 into curcumin and essential oil in relation to primary metabolites in developing turmeric (Curcuma longa) leaves. Plant Sci. 152, 165-171.

Dixit, D., Srivastava, N.K., 2000b. Partitioning of 14C-photosynthate of leaves in roots, rhizome, and in essential oil and curcumin in turmeric (Curcuma longa L.). Photosynthetica 38, 275-280, http://dx.doi.org/10.1023/A:1007262831715.

Flores, H., Galston, A., 1982. Analysis of polyamines in higher plants by high performance liquid chromatography. Plant Physiol. 69, 701-706.

Friedman, R., Levin, N., Altman, A., 1986. Presence and identification of polyamines in xylem and Phloem exudates of plants. Plant Physiol. 82, 1154-1157.

Frohnmeyer, H., Staiger, D., 2003. Ultraviolet-B radiation-mediated responses in plant. Balancing damage and protections. Plant Physiol. 133, 1420-1428, http://dx.doi.org/10.1104/pp.103.030049.

Goyal, M., Asthir, B., 2010. Polyamine catabolism influences antioxidative defense mechanism in shoots and roots of five wheat genotypes under high temperature stress. Plant Growth Regul. 60, 13-25.

Curcumin Market Analysis By Application (Pharmaceutical, Food, Cosmetics) And Segment Forecasts To 2022 [WWW Document], 2015. Gd. View Res. Inc. URL http://www.grandviewresearch.com/industry-analysis/turmeric-extractcurcumin-market.

He, X.-G., Lin, L.-Z., Lian, L.-Z., Lindenmaier, M., 1998. Liquid chromatography-electrospray mass spectrometric analysis of curcuminoids and sesquiterpenoids in turmeric (Curcuma longa). J. Chromatogr. A 818, 127-132, http://dx.doi.org/10.1016/S0021-9673(98)00540-8.
Hossain, M.A., Akamine, H., Ishimine, Y., Teruya, R., Aniya, Y., Yamawaki, K., 2009. Effects of relative light intensity on the growth, yield and curcumin content of turmeric (Curcuma longa L.) in Okinawa, Japan. Plant Prod. Sci. 12, 29-36, http://dx.doi.org/10.1626/pps.12.29.

Jansen, M.A., Gaba, V., Greenberg, B.M., 1998. Higher plants and UV-B radiation: balancing damage, repair and acclimation. Trends Plant Sci. 3, 131-135, http:// dx.doi.org/10.1016/S1360-1385(98)01215-1.

Jansen, M.A.K., Hectors, K., O’Brien, N.M., Guisez, Y., Potters, G., 2008. Plant stress and human health: Do human consumers benefit from UV-B acclimated crops? Plant Sci. 175, 449-458, http://dx.doi.org/10.1016/j.plantsci.2008.04.010.

Jansen, M.A.K., 2002. Ultraviolet-B radiation effects on plants: induction of morphogenic responses. Physiol. Plant. 116, 423-429, http://dx.doi.org/10. 1034/j.1399-3054.2002.1160319.x.

Katsuyama, Y., Kita, T., Funa, N., Horinouchi, S., 2009. Curcuminoid biosynthesis by two type III polyketide synthases in the herb Curcuma longa. J. Biol. Chem. 284 11160-11170, http://dx.doi.org/10.1074/jbc.M900070200.

Kotzabasis, K., Strasser, B., Navakoudis, E., Senger, H., Dörnemann, D., 1999. The regulatory role of polyamines in structure and functioning of the photosynthetic apparatus during photoadaptation. J. Photochem. Photobiol. B Biol. 50, 45-52, http://dx.doi.org/10.1016/S1011-1344(99)00067-6.

Kulkarni, S.J., Maske, K.N., Budre, M.P., Mahajan, R.P., 2012. Extraction and purification of curcuminoids from turmeric (Curcuma longa L.). Int. J. Pharmacol. Pharm. Technol. 1, 2277-3436.

Lavola, A., Julkunen-Tiitto, R., de la Rosa, T.M., Lehto, T., Aphalo, P.J., 2000. Allocation of carbon to growth and secondary metabolites in birch seedlings under UV-B radiation and CO2 exposure. Physiol. Plant. 109, 260-267, http:// dx.doi.org/10.1034/j.1399-3054.2000.100306.x.

Lima, G.P.P., Brasil, O.G., Oliveira, A.M.de, 1999. Poliaminas e atividade de peroxidase em feijão (Phaseolus vulgaris L.) cultivado sob estresse salino. Sci. Agric. 56 (-26), http://dx.doi.org/10.1590/s0103-90161999000100004.

Lima, G.P.P., da Rocha, S.A., Takaki, M., Ramos, P.R.R., Ono, E.O., 2008. Comparison of polyamine, phenol and flavonoid contents in plants grown under conventional and organic methods. Int. J. Food Sci. Technol. 43, 1838-1843, http://dx.doi.org/10.1111/j.1365-2621.2008.01725.x.

Maheshwari, R.K., Singh, A.K., Gaddipati, J., Srimal, R.C., 2006. Multiple biological activities of curcumin: a short review. Life Sci. 78, 2081-2087, http://dx.doi. org/10.1016/j.lfs.2005.12.007.

Martin-Tanguy, J., 2001. Metabolism and function of polyamines in plants: recent development (new approaches). Plant Growth Regul. 34, 135-148, http://dx. doi.org/10.1023/A:1013343106574.

Padmapriya, S., Chezhiyan, N., Sathiyamurthy, V.A., 2007. Effect of shade and integrated nutrient management on biochemical constituents of turmeric (Curcuma longa L.). J. Hortic. Sci. 2, 123-129.

Payton, F., Sandusky, P., Alworth, W.L.W., 2007. NMR Study of the solution structure of curcumin. J. Nat. Prod. 70, 143-146, http://dx.doi.org/10.1021/ np060263s.

Peixoto, P.H.P., Cambraia, J., Sant'Anna, R., Mosquim, P.R., Moreira, M.A., 1999. Aluminum effects on lipid peroxidation and on the activities of enzymes of oxidative metabolism in sorghum. Rev. Bras. Fisiol. Veg. 11, 137-143.

Salem, M., Rohani, S., Gillies, E.R., 2014. Curcumin, a promising anti-cancer therapeutic: a review of its chemical properties, bioactivity and approaches to cancer cell delivery. RSC Adv. 4, 10815, http://dx.doi.org/10.1039/c3ra46396f.

Santos, H.G., Jacomine, P.K.T., Anjos, L.H.C., Oliveira, V.A., Oliveira, J.B., Coelho, M.R Lumbreras, J.F., 2006. Sistema Brasileiro De Classificação De Solos, 2nd ed. Embrapa solos, Rio de Janeiro.

Sfichi, L., Ioannidis, N., Kotzabasis, K., 2004. Thylakoid-associated polyamines adjust the UV-B sensitivity of the photosynthetic apparatus by means of light-harvesting complex II changes. Photochem. Photobiol. 80, 499-506, http://dx.doi.org/10.1562/0031-8655(2004)080<0499:TPATUS>2.0.CO;2.

Singh, S., Panda, M.K., Nayak, S., 2012. Evaluation of genetic diversity in turmeric (Curcuma longa L.) using RAPD and ISSR markers. Ind. Crops Prod. 37, 284-291, http://dx.doi.org/10.1016/j.indcrop.2011.12.022.

Singleton, V.L., Rossi, J.A.J., 1965. Colorimetry of total phenolics with phosphomolybdic-phosphotungstic acid reagents. Am. J. Enol. Vitic. 16, 144-158.

Srikrishnah, S., Sutharsan, S., 2015. Effect of different shade levels on growth and tuber yield of turmeric (Curcuma longa L.) in the Batticaloa District of Sri Lanka. Am. J. Agric. Environ. Sci. 15, 813-816, http://dx.doi.org/10.5829/idosi.aejaes. 2015.15.5.12642.

Stapleton, A.E., 1992. Ultraviolet radiation and plants: burning questions. Plant Cell 4, 1353-1358, http://dx.doi.org/10.1105/tpc.4.11.1353.

Takahashi, S., Milward, S.E., Yamori, W., Evans, J.R., Hillier, W., Badger, M.R., 2010. The solar action spectrum of photosystem II damage. Plant Physiol. 153, 988-993, http://dx.doi.org/10.1104/pp.110.155747.

Zhu, P., Yang, L., 2015. Ambient UV-B radiation inhibits the growth and physiology of Brassica napus L. on the Qinghai-Tibetan plateau. Field Crops Res. 171, 79-85, http://dx.doi.org/10.1016/j.fcr.2014.11.006. 